\title{
Financiamento à Inovação no Brasil: análise da aplicação dos recursos do Fundo Nacional de Desenvolvimento Científico e Tecnológico (FNDCT) e da Financiadora de Estudos e Projetos (FINEP) de 1967 a 2006*
}

\author{
Luiz Martins de Melo \\ Universidade Federal do Rio de Janeiro
}

Recebido: 29/8/2007 Aprovado: 10/4/2008

\section{Resumo}

O presente trabalho tem como objetivo analisar o financiamento das atividades de inovação por meio da aplicação dos recursos do Fundo Nacional de Desenvolvimento Científico e Tecnológico (FNDCT) e da Financiadora de Estudos de Projetos (FINEP), de 1967 a 2006. Com base no conceito de Sistema Nacional de Inovação, é apresentada uma divisão em dois períodos, 1967-1997 e 1998-2006, cujo centro é a mudança institucional que criou os fundos setoriais como fonte primária de recursos para o FNDCT e, conjuntamente, a mudança na sua governança. Uma comparação entre os dois períodos é feita, procurando-se realçar os traços gerais que influenciaram essa alocação de recursos, visando analisar como essas diferenças influenciaram as prioridades gerais dos financiamentos do FNDCT e da FINEP. Os principais resultados encontrados na pesquisa foram um maior desembolso médio de recursos anual e a prioridade para o apoio às empresas nacionais no primeiro período. No segundo período, apesar da elevação na arrecadação dos fundos setoriais, a aplicação efetiva dos recursos é prejudicada pela política macroeconômica muito restritiva e pela ausência de integração entre os instrumentos de financiamento da inovação.

Palavras-Chave | Sistema Nacional de Inovação; Financiamento; FNDCT; FINEP

Códigos JEL | O38; O16; O32

\footnotetext{
* O autor agradece a Márcia Rapini, doutoranda do IE-UFRJ, o inestimável trabalho, que viabilizou a versão final deste artigo. O autor agradece aos comentários e observações dos pareceristas, que foram de extrema importância para a melhoria do texto e para a clareza de alguns conceitos. O resultado final, porém, é de única responsabilidade do autor.
} 


\section{Abstract}

The current work is focused on analyzing the innovation financing activities through the analysis of the outlays of the Fundo Nacional de Desenvolvimento Científico e Tecnológico - FNDCT (Funding for Scientific and Technological Development) and also through Financiadora de Estudos de Projetos - FINEP (Research and Projects Financing) during 1967-2006. Based on the concept of National System of Innovation a division in two periods will be proposed, which are 1967-1997 and 1998-2006, that has its landmark in the institutional change which created the sectoral funds as the primary source of funds to the FNDCT as well as setting up of a new governance to manage them. In order to understand those changes a comparison between the two periods will be made to point out the main features in both periods, that influenced the allocation of funds to FNDCT and FINEP and how those different features influenced the general priorities of FNDCT and FINEP outlays in each period. The conclusion points out to a higher average outlay per year and a priority to finance Brazilian owned firms in the first period. Despite the increase in the tax collection to sectoral funds in the second period, the amount of resources at disposal of the FNDCT and FINEP were hindered by a very tight macroeconomic policy, and by the lack of operational integration among the financial instruments to support innovation.

KeYwords | National Innovation System; Financing; FNDCT; FINEP

JEL-CODES | O38; O16; O32

\section{Introdução}

As investigações sobre os Sistemas Nacionais de Inovação focam o papel das instituições e os processos interativos de aprendizado e de geração de conhecimento nas empresas. A dimensão financeira não recebeu destaque nessa abordagem. Freeman (1994) realizou uma survey sobre a situação da agenda de pesquisas neosschumpeteriana e afirmou que o tópico não tinha ocupado um lugar central na agenda. Como destacaram Levine e Zervos (1998:537), essa é uma lacuna relevante nessa corrente teórica, dado que o próprio Schumpeter (1982) já ressaltava a importância do sistema bancário no crescimento econômico, destacando as circunstâncias nas quais os bancos poderiam ativamente estimular o investimento em inovação. 
A importância do financiamento para os investimentos em inovação vem sendo apontada como um significativo gargalo estrutural ainda não solucionado pelas instituições financeiras privadas. ${ }^{1}$ Se, por um lado, a internacionalização, desregulamentação e globalização dos mercados financeiros sinalizam a possibilidade de recursos a custos mais baixos, por outro, as características do investimento em inovação, como longo prazo de maturação, incerteza e risco, indicam a necessidade da existência de arranjos institucionais nacionais (Melo, 1994). A construção de instrumentos alternativos de financiamento para os investimentos em inovação implica ações governamentais (Corder \& Salles-Filho, 2006).

Ao analisar a relação entre o sistema financeiro e o investimento em inovação, é preciso levar em conta a natureza do processo de inovação, a competição nos mercados e os critérios de análise de risco e crédito das instituiçôes financeiras para a concessão do financiamento.

"In a very general sense, innovation concerns of learning and discovery about new products, new production processes and new forms of economic organization, about which, ex ante, economic actors often possess only rather unstructured beliefs on some unexploited opportunities, and which, ex post, are generally checked and selected, in product markets. However, in addition, and complementary, to product market competition, innovative efforts are shaped and selected also by rates and criteria by which financial markets and financial institutions (private and public), such as stock markets and banks, allocate to business enterprises. Irrespectively of whether resources are attributed to firms or individual projects, allocative criteria and rates of allocation should plausibly affect the amount of resources which the industry devotes to the innovative search, and also the directions in which the agents search." (Dosi, 1990:301)

Tais características do processo de inovação fazem com que os bancos e os próprios mercados de ações sejam avessos a financiá-la, em especial nos países de capitalismo tardio, que não construíram sistemas financeiros capazes de avaliar ativos intangíveis.

É importante notar que uma empresa pode recorrer a fontes distintas para financiar seus programas de investimento. Essas fontes podem ser classificadas da seguinte maneira:

1 Uma apresentação ampla desses mecanismos de apoio financeiro e de incentivo fiscal para a inovação no Brasil pode
ser encontrada em Guimarães (2006). 
1) reinversão dos lucros retidos (autofinanciamento);

2) emissão de ações (captação de recursos dos acionistas ou com o público);

3) emissão de títulos financeiros (mecanismos de financiamento direto);

4) empréstimos bancários (mecanismos de financiamento indireto).

A utilização de cada uma dessas fontes e a sua participação relativa na estrutura de capital das empresas dependerão do desenvolvimento histórico e institucional da relação entre o sistema financeiro e o sistema industrial.

A evolução histórica do sistema financeiro brasileiro mostrou o fraco desenvolvimento do mercado de capitais e do crédito bancário para o financiamento dos investimentos tangíveis. Em relação ao financiamento de ativos intangíveis, tal como a inovação, a participação do sistema financeiro foi praticamente inexistente. Restou às empresas a utilização do autofinanciamento por via de lucros retidos, o que levou as empresas nacionais a aumentarem os seus investimentos, em especial em inovação.

A necessidade de criação de instituições específicas, públicas, resultado de uma ação estratégica do Estado brasileiro, mostrou que a relação entre o sistema financeiro e o sistema industrial não evoluiu da forma como historicamente ocorreu nos países desenvolvidos (Miranda \& Tavares, 1999).

Como consequência dessa avaliação, foi criado, no início da década de 1950, o Banco Nacional de Desenvolvimento Econômico e Social (BNDES), voltado fundamentalmente para o financiamento dos ativos tangíveis, o investimento em infraestrutura e a criação e ampliação da capacidade produtiva das empresas nacionais. Sabe-se que o financiamento do investimento em ativos tangíveis máquinas, equipamentos e instalações - para a modernização inclui também uma proporção de investimento intangível, incorporado nos ativos tangíveis (Melo, 1994; OECD, 1996).

Em meados da década de 1960, foi constatada a necessidade de estruturar os mecanismos financeiros para o financiamento do investimento em ativos intangíveis. Inicialmente, o BNDES assumiu essa missão. Depois, percebeu-se que as lógicas de financiamento não eram idênticas. Foi criado, então, o FNDCT, e a FINEP recebeu a atribuição de exercer a sua Secretaria Executiva. ${ }^{2}$

Neste artigo, o objeto central será o exame da aplicação dos recursos do FNDCT e da FINEP. A escolha do FNDCT e da FINEP é quase que óbvia, em função da 2 Esse processo está descrito em Melo (1988). 
argumentação desenvolvida anteriormente nesta introdução. Eles inauguraram o financiamento para a inovação no Brasil como uma política pública explicitamente definida e permaneceram ativos desde a sua criação.

O artigo está estruturado em mais três seçôes, além da introdução ora apresentada. Na segunda seção, são apresentadas as questões teóricas concernentes à relação entre o financiamento e a inovação. $\mathrm{Na}$ terceira seção, discute-se a aplicação dos recursos do FNDCT e da FINEP para o financiamento da inovação no Brasil. Essa terceira parte, por sua vez, está estruturada em três subseçôes. A primeira enfoca os anos de 1967 a 1997, abrangendo o período de constituição do FNDCT e a atribuição dada à FINEP para ser a sua Secretaria Executiva, encerrando-se com a entrada em operação dos fundos setoriais. A segunda, a partir de 1998, abrange o período de aplicação dos recursos do FNDCT na vigência dos fundos setoriais e as alteraçōes que tal mudança institucional trouxe para o funcionamento do sistema de financiamento à inovação no Brasil. A terceira apresenta um panorama dos novos instrumentos financeiros que entraram em operação no segundo período. Finalmente, serão apresentadas algumas conclusões.

\section{Financiamento e inovação}

Em sua obra sobre o sistema nacional de inovações do Japão, Freeman (1987), que fundou teoricamente esse conceito ${ }^{3}$ (Lundvall, 1992), afirmou que todo sistema nacional de inovação deve estar capacitado para operar de forma a atender aos requisitos da inovação em quatro áreas:

1) a intervenção do Estado através da política pública;

2) o modo como as empresas formulam suas estratégias de pesquisa e desenvolvimento $(\mathrm{P} \& \mathrm{D})$;

3) o impacto da educação na formação de recursos humanos e no treinamento dos técnicos, pesquisadores e trabalhadores e as inovaçôes sociais relacionadas a essa formação de recursos humanos;

4) a estrutura conglomerada, a organização interna das firmas e as relações entre elas, que compõem a estrutura industrial vigente em um dado momento em cada país.

3 Albuquerque (2004) afirmou que o conceito de Sistema Nacional de Inovação é uma ideia fundadora na teoria neosschumpeteriana. 
É claro que tais características ou subsistemas do sistema de inovação têm de operar de forma compatível e coordenada, de modo a gerar um efeito positivo sobre as expectativas dos agentes principais do sistema, as firmas, e, a partir daí, induzi-las ao aumento do investimento. Porém não existe investimento sem financiamento. Assim, Melo (1996) buscou apoio nos conceitos pós-keynesianos, desenvolvidos em Minsky (1982) e Studart (1993), para acrescentar uma quinta característica às quatro anteriores, a organização institucional e a estrutura do setor financeiro.

Mais tarde, Freeman e Perez (1988) afirmaram que a coevolução entre as instituiçôes financeiras e tecnológicas constituiu uma das características-chave das cinco ondas longas do capitalismo, por pressionarem por mudanças nas estruturas organizacionais das firmas e por inovações financeiras, como resposta às necessidades de capital, que evoluíam conjuntamente com as mudanças tecnológicas. Um exemplo clássico dessas relações é o surgimento da sociedade anônima e da responsabilidade limitada dos investidores, na segunda metade do século XIX, em paralelo com o aumento dos requerimentos mínimos de capital, para atender às necessidades dos investimentos da segunda revolução industrial. Surge então o maior banco de investimento do mundo nos Estados Unidos, o Morgan, consolidando as estruturas passivas e ativas de vários processos de concentração e centralização de capitais na época (Chandler, 1990).

Rosenberg (1990) destacou que a pesquisa básica é uma forma de investimento de longo prazo e que o seu financiamento deve ser estruturado para atender a esse requisito e à sua elevada incerteza. Quando, no entanto, obtém resultado, a pesquisa básica é a que fornece maior retorno social, sendo este apropriado pelas empresas com elevados retornos privados.

$\mathrm{Na}$ literatura mais voltada para a análise da relação entre financiamento do investimento em inovação e sistema financeiro, destacam-se os autores referidos a seguir. Zysman $(1983,1986)$ discutiu o impacto dos diferentes tipos de sistema financeiro - dominado pelo crédito ou pelo mercado de capitais - sobre a dinâmica das inovações e dos setores industriais. Christensen (1992) analisou a diversidade das formas de atuação das instituições financeiras nos sistemas nacionais de inovação, realçando em especial o conhecimento mútuo pelas repetidas operações de crédito entre empresas e instituiçōes financeiras que facilita a concessão do financiamento. Nelson (1993) apontou para os diferentes arranjos institucionais de cada país, para fornecer o financiamento de longo prazo para o investimento em inovação. Patel e Pavitt (1994) assinalaram a diferença entre os sistemas nacionais de inovação míopes, que privilegiam o retorno dos investimentos no curto prazo, e os dinâmicos, que 
valorizam os investimentos de longo prazo. Melo (1994) procurou compatibilizar a análise teórica pós-keynesiana sobre o sistema financeiro com o conceito neoschumpeteriano de sistema nacional de inovação, para discutir o financiamento da inovação. A preocupação teórica central foi buscar um denominador comum entre a teoria da incerteza keynesiana e da inovação através do conceito de ativos intangíveis. Os ativos intangíveis são definidos como aqueles que alteram o posicionamento competitivo futuro da firma, conferindo-lhe um grau de diferenciação maior em relação aos seus competidores, que proporciona uma maior flexibilidade para definir a sua estratégia de preços e, consequentemente, o seu poder de mercado. Mais recentemente Chesnais e Sauviat (2005) avançaram na análise do venture capital, como uma inovação notadamente americana e adaptada ao sistema financeiro baseado no mercado de capitais e na etapa da globalização financeira.

Alguns autores, em artigos mais recentes, deixaram de lado os aspectos institucionais, isto é, a relação entre o financiamento da inovação, o sistema nacional de inovação e o sistema financeiro, para assumir diretamente que o venture capital seria a forma privilegiada de incorporar, na prática, tal relação. Esse é o caso de Peirone (2007), que trata o venture capital como uma relação contratual entre a firma e o sistema financeiro, esquecendo-se dos aspectos institucionais, bem como o de diversos trabalhos, entre os quais da OECD (1996) e do CGEE (2003a, 2003b). O'Sullivan (2005) apresentou um resumo dos problemas gerais do financiamento da inovação na perspectiva neosschumpeteriana e procurou descrever as formas de financiamento mais apropriadas para superá-los.

Mayer (2002) questiona as chamadas pré-condições financeiras para o desenvolvimento de um setor de alta tecnologia. Critica a quase unanimidade na resposta de que essas pré-condiçóes envolvam a existência de um ativo setor de venture capital ligado a um mercado de capitais capaz de prover muita liquidez. Pode-se dizer que Mayer (2002) e Chesnais e Sauviat (2005) se alinham em suas conclusôes, mesmo partindo de pressupostos teóricos distintos. O venture capital, como sistema de financiamento da inovação, é uma inovação adequada aos Estados Unidos da América.

No caso do Brasil, poucos são os textos que abordam diretamente o financiamento da inovação em suas dimensões sistêmicas, que é o tema de interesse neste artigo. ${ }^{4}$ Em período mais recente, houve um aumento do interesse por esse tema.

4 Há textos que tratam de aspectos específicos do financiamento para inovação, como CGEE (2003a, b), OECD (1996), Pavani (2003), Rechtman e Brito (2005). O'Sullivan (2005) apresenta um resumo geral dos problemas gerais do financiamento da inovação. 
Erber (1999) procura estabelecer uma relação teórica entre a teoria da inovação neosschumpeteriana e a teoria do financiamento dos pós-keynesianos. Na mesma linha, Corder e Salles-Filho (2006) articulam os conceitos de finance e funding póskeynesianos com a teoria da inovação neosschumpeteriana e propõem novos mecanismos institucionais de política de financiamento da inovação. Paula et al. (2001) partem da análise marxista do capital financeiro e o relacionam com a evolução do sistema financeiro e da criação do capital fictício. Nesse sentido, seria possível tentar discutir a noção de capital fictício, cotejando-a com a noção de ativo intangível, da mesma forma que o ativo tangível está ligado ao crédito bancário, ao fornecer sua própria garantia contratual.

Bastos (2003) desenvolveu uma análise, com a mesma orientação teórica neo-shumpeteriana e pós-keynesiana, para discutir os fundos setoriais e o contexto político e institucional da sua criação. Destaca alguns aspectos críticos relacionados à governança dos fundos setoriais, em especial, à operação de comitês gestores específicos para cada fundo, sem haver um comitê geral, de caráter estratégico, que através da coordenação evite a fragmentação dos recursos. Milanez (2007) questionou se os fundos setoriais são as instituições adequadas para promover o desenvolvimento científico e tecnológico do Brasil. O foco do seu questionamento são os elevados custos de transaçooes decorrentes de uma estrutura de gestão que induz à fragmentação da aplicação dos recursos. Milanez (2007) e Bastos (2003) concordam que a ausência de uma governança adequada à definição das prioridades para a aplicação dos recursos e para a elaboração de novos instrumentos financeiros, mais compatíveis com as características do investimento em C\&T e inovação, prejudica a eficácia da operação dos fundos setoriais.

Outra linha de abordagem do problema do financiamento e da inovação, que foge ao escopo deste trabalho, é elaborada por Brito et al. (2001) e Mytelka (2002). Esta é voltada especificamente para os sistemas regionais de inovação e arranjos produtivos locais (APLs).

A inadequação entre os mecanismos financeiros existentes nos fundos setoriais e os seus objetivos já tinha sido levantada por Melo (2003), ao analisar as características específicas do ativo formado no processo de inovação. Investir em inovação implica assumir uma incerteza maior do que em investimentos tangíveis, os quais já incorporam o conhecimento tácito codificado em manuais técnicos de operação e servem de garantia para o empréstimo. Se a inovação é fundamentalmente tácita, ela é de difícil transferência e fortemente específica ao seu contexto, seja este uma firma, uma região ou um país. Decorre desse fato a importância do conceito de sistema nacional de inovação. Ao 
relacionar a questão nacional com a inovação, Freeman $(1987,1995)$ considera crucial a origem do controle do capital das empresas para a articulação com as instituições envolvidas, em toda a cadeia de geração, apropriação e difusão da inovação. Isto é, para a geração do conhecimento tácito e intangível.

Esta é questão teórica central para o financiamento da inovação. Mayer (1989) fornece uma nova pista para o problema teórico do financiamento da inovação. Salienta que a tarefa básica de um sistema financeiro evoluído não é o financiamento do investimento em projetos, mas o apoio financeiro dado à criação, ao crescimento e à consolidação de empresas. Realça, ainda, a importância da existência de uma determinada articulação institucional com o sistema financeiro, com vistas à clara definição dos mecanismos de garantia do controle do capital das empresas pelos grupos nacionais, sobretudo, pelo mercado de capitais. Essa relação tem de ser construída no contexto histórico e institucional de cada país. Não existe uma fórmula geral para ser aplicada globalmente.

É fundamental, no entanto, que as firmas tenham segurança em relação às condições de apropriação do resultado do processo de inovação. Este é caracterizado por inúmeras e contínuas interações e retroalimentaçóes (feedbacks). ${ }^{5} \mathrm{Tal}$ processo interativo ocorre dentro e fora da empresa. Dentro da empresa, ligando os seus diversos departamentos: produção, marketing, $\mathrm{P} \& \mathrm{D}$, manutenção etc.; fora da empresa, envolvendo as instituiçôes de pesquisa, de ensino, outras empresas, instituições financeiras, instituições legais e de proteção à propriedade intelectual, fornecedores e clientes etc. Essa rede a ser construída pela firma, a fim de INOVAR e se apropriar do seu resultado, deve ser compatível com as instituições do sistema nacional de inovação. A compatibilidade é uma das dimensões mais importantes da estratégia de inovação da firma e constitui, sem dúvida, um elemento definidor de sua capacitação para desenvolver conhecimento tácito (Rosenberg, 1990).

Chang (2004) mostra que é enganosa a ideia de que a globalização resolve o problema. Ela confunde modernização, acesso aos produtos disponíveis no mercado internacional, seja pela produção interna ou pela importação, com a capacitação tecnológica para a INOVAR. Aceitar isso significaria desobrigar-se da constituição das instituições que são a base da capacitação tecnológica e do desenvolvimento econômico que no capitalismo são as empresas.

Longe de qualquer xenofobismo, procura-se ressaltar apenas o caráter nacional e específico da formação dos ativos intangíveis, resultado da criação do conhecimento

5 Patel e Pavitt (1994) apresentam dados sobre a importância dos Sistemas Nacionais de Inovação para a apropriação da inovação pelas firmas nacionais e mostram que, esmagadoramente, as patentes das firmas multinacionais se originaram em seus centros de $P \& D$, em seus países de origem. 
tácito pelas empresas, que ocorre fundamentalmente em seu contexto nacional, o qual facilita a sua apropriação pela existência de instituições que evoluíram conjuntamente com as empresas.

Em tais condições, os mecanismos de mercado são inadequados para induzir o aumento dos investimentos em inovação. O FNDCT e a FINEP são instituições que foram criadas pelo Estado brasileiro para atuar diretamente no financiamento da inovação.

\section{Análise da aplicação dos recursos do Fundo Nacional de Desenvolvimento Científico e Tecnológico e da Financiadora de Estudos e Projetos de 1967 a 2006}

A análise da evolução do sistema de financiamento à inovação no Brasil é realizada em dois momentos. O primeiro, de 1967 a 1997, abrange o período de constituição do FNDCT e de seu financiamento por meio de dotação orçamentária ordinária. O segundo inicia-se com a aprovação da nova legislação relativa aos fundos setoriais como nova fonte de recursos para o FNDCT.

A criação dos fundos setoriais representou não só uma mudança nas fontes de financiamento do FNDCT, mas também nas definiçôes de prioridades para a aplicação dos seus recursos através de sua Secretaria Executiva, a FINEP. Outro tipo de articulação institucional entre a FINEP e o FNDCT. Estas são as razões institucionais que fundamentam a periodização.

\subsection{0 primeiro período: $1967-1997$}

O padrão de financiamento que vigorou do final da década de 1960 até 1997 foi baseado em recursos do orçamento fiscal alocados diretamente no FNDCT e operados pela FINEP, para aplicação direta em projetos de Ciência e Tecnologia (C\&T). Os recursos foram também utilizados na composição da contrapartida dos empréstimos externos obtidos nos organismos internacionais, para complementar os recursos orçamentários, em especial, do Banco Interamericano de Desenvolvimento (BID) e do Banco Mundial (BIRD), bem como no aumento do capital da Financiadora de Estudos e Projetos. ${ }^{6}$ Além disso, como Secretaria Eexecutiva do FNDCT, a FINEP tinha autonomia bastante ampla para definir as prioridades da aplicação dos recursos do fundo. Um exemplo foram as transferências de $20 \%$ em

6 Sobre esse ponto, ver Melo (1988, 1994). 
média por ano dos recursos do FNDCT, realizadas simplesmente por decisão de sua Diretoria, para compor o funding do programa de Apoio ao Desenvolvimento Tecnológico da Empresa Nacional - ADTEN (Melo,1988).

Conforme mencionado na seção anterior, é fundamental que exista uma relação de parceria, principalmente com o sistema financeiro, para o financiamento da inovação. Esse aspecto é decisivo para entender a criação do FNDCT em 1969. O BNDES operava um fundo de financiamento para o desenvolvimento científico e tecnológico. Além de não ter institucionalidade própria, este era gerido por uma instituição cuja cultura era, e continuou predominantemente, dominada pelo financiamento de ativos tangíveis, direcionados para o aumento da capacidade de produção das empresas e da infraestrutura do país. Nesse caso, os próprios ativos financiados podem servir de garantia para os financiamentos concedidos.

Tarefa completamente diferente é o financiamento da inovação, que é um ativo intangível. Não existiam recursos nem instituições especializadas, públicas ou privadas para a sua execução (Melo, 1988, 1994). Assim, o FNDCT foi instituído pelo Decreto-Lei n.719, de 31/7/1969, e ratificado pela Lei n.8.172, de 18/1/1991. Os recursos que comporiam o fundo foram definidos como orçamentários, provenientes de incentivos fiscais, empréstimos e doações.

A FINEP, que já existia como agência voltada para o apoio a projetos de pré-investimento (engenharia de consultoria), foi tornada Secretaria Executiva do FNDCT pelo Decreto n.68.748, de 15/7/1971. A nova atribuição mostra que, desde o início da conformação institucional do sistema nacional de inovação, existia uma preocupação de que o financiamento da inovação envolvia o apoio a um processo muito mais amplo do que o de C\&T (Rosenberg, 1990; Freeman, 1994, 1995). Esta não é, portanto, uma preocupação recente que surgiu com os fundos setoriais no final da década de 1990.

Esse vínculo será reforçado com a criação do programa ADTEN pela Exposição de Motivos (EM) n.252, de 31 de agosto de 1976, do ministro do Planejamento para o presidente da República. Pode-se dizer que este é o primeiro documento explícito de política de financiamento da inovação no Brasil, ao apontar para a necessidade de se diferenciar o financiamento do investimento intangível do tangível. Consta no documento que:

"1. As linhas de ação ora propostas inserem-se, complementando-as, no conjunto de medidas que integram a 'Ação Para a Empresa Privada Nacional', aprovadas por Vossa Excelência, no Conselho de Desenvolvimento Econômico e dão substância à 
diretriz de fortalecimento tecnológico da Empresa Nacional, previsto no II Plano Básico de Desenvolvimento Científico e Tecnológico - PBDCT". (EM n.252, de 31 de agosto de 1976)

No mesmo documento, em outro parágrafo, é definido o objetivo do programa ADTEN:

"5. A forma tradicional de as empresa públicas e privadas brasileiras contornarem essas dificuldades tem sido, basicamente, a de comprar tecnologia estrangeira através de licenciamento ou de associação de empresas, resultando daí uma absorção parcial de tecnologia. Com isto, porém, evitam incertezas inerentes à atividade de pesquisa e desenvolvimento e o impacto adicional que representaria sobre as suas disponibilidades de recursos humanos e financeiros". (EM n.252, de 31 de agosto de 1976)

É interessante salientar que não se tratou de resolver problemas de alguma falha de mercado, mas de atacar a dificuldade enfrentada pelas empresas nacionais, uma vez que a propriedade do capital da empresa era um fator excludente para ter acesso ao financiamento. Em um país periférico onde há maiores incertezas para a realização do investimento em inovação, as empresas preferem o licenciamento de tecnologia ao seu desenvolvimento. Assim, tinha-se de criar as condiçôes de financiamento para que elas tivessem uma alternativa para a tomada de decisão de investir em inovação autonomamente, ao conferir-lhes um tratamento diferenciado com base na propriedade do capital.

Note-se que no caso brasileiro praticamente todo o financiamento de longo prazo era realizado por meio de fundos públicos e instituições financeiras públicas, e estas últimas podiam também acessar os fundos internacionais para complementar seus recursos. O sistema financeiro privado é o grande ausente no financiamento do investimento de longo prazo. Esta é outra característica sistêmica, não a única, decorrente da forma histórica em que se deu a inserção do capitalismo tardio brasileiro na economia internacional.

De acordo com Miranda e Tavares (1999:327), "no caso brasileiro, a consolidação das grandes empresas esteve ligada a algum tipo de solidariedade entre finanças e indústria, porém do tipo rentista-patrimonialista. Isto é, não conduziu à formação de um verdadeiro capitalismo financeiro, característica do capitalismo monopolista moderno". 
Dando continuidade à apresentação dos itens principais da EM n.252, o parágrafo 19 estabelece que os recursos para o programa ADTEN poderiam ser investidos nas empresas sob a forma de participação no risco, uma antecipação do que atualmente é denominado venture capital:

"19. Quanto à forma de participação no risco, ela deverá principalmente corresponder a uma ação de 'Promoção de Projetos', entendida essa expressão, desde logo, de forma bem ampla. Tal entendimento exige que se afaste a hipótese de se tratar tão-somente de uma variedade de ação financiadora, em que prazos e garantias são um tanto mais flexiveis. Promoção de projetos é risco. Significa capital acrescido de envolvimento e assistência gerencial e técnica. O programa, enquanto promotor de projetos, deverá estar apto a suprir capital tanto quanto a prover meios que assegurem assistência gerencial ou técnica para ajudar empresários a desenvolver empreendimentos novos ou existentes, desde que tais alternativas contenham características que impliquem em desenvolvimento de produtos, processos ou serviços; assim entendida, a promoção está definitivamente ligada ao conceito de inovação, e não apenas como descoberta, mas sim como abrangendo qualquer introdução bem sucedida, de produto, processo, sistema ou serviço novo ou desenvolvido (e significativamente melhorado), em determinado momento. Com esta diretriz o programa assegurará apoio financeiro à empresa nacional segundo a modalidade ou fórmula que não necessariamente empréstimo convencional, e vantajosa ou indispensável à consecução do seu projeto de desenvolvimento tecnológico".

Nota-se pelas citações que a constituição do FNDCT e a concepção da EM n.252 se complementavam. Também já contemplavam as possíveis formas de financiamento que poderiam ser utilizadas para $\mathrm{C} \& \mathrm{~T}$ e inovação: financiamento nãoreembolsável para o desenvolvimento científico, crédito subsidiado ${ }^{7}$ e participação no risco para as empresas.

$\mathrm{Na}$ Tabela $1^{8}$ estão apresentados os dados da evolução dos recursos destinados ao financiamento da inovação pelo FNDCT e pela FINEP no período de 1967 a 1997. Os recursos do FNDCT referem-se ao financiamento para o desenvolvimento

7 Esse subsídio era muito expressivo, podendo atingir até $80 \%$ da correção monetária dos contratos de financiamento. As taxas de juros variavam de $2 \%$ a $6 \%$. A inflação no final da década de 1970 era por volta de $40 \%$ ao ano. No início da década de 1980, com a crise da moratória do México, esse subsídio foi cancelado (Melo, 1988).

8 As informações constantes das tabelas do FNDCT e da FINEP foram obtidas na área de orçamento da FINEP. O autor agradece a gentileza dos técnicos André Amaral de Araújo, Marilena Ferraz Andrade e José Antonio Bustamante no atendimento das solicitações de dados para este trabalho. A responsabilidade pelas análises e os conceitos emitidos com base nessas informações é exclusiva do autor. 
TABELA 1

Evolução dos desembolsos da FINEP e do FNDCT, 1967-1997

(em R\$ milhões constantes média anual, IPCA - dez. 2006)*

\begin{tabular}{|c|c|c|c|}
\hline Ano & FNDCT & FINEP & FINEP + FNDCT \\
\hline 1967 & - & 54,8 & 54,8 \\
\hline 1968 & - & 101,7 & 101,7 \\
\hline 1969 & - & 34,3 & 34,3 \\
\hline 1970 & 154,3 & 14,7 & 169,0 \\
\hline 1971 & 257,7 & 38,7 & 296,4 \\
\hline 1972 & 453,9 & 47,7 & 501,6 \\
\hline 1973 & 599,7 & 229,0 & 828,8 \\
\hline 1974 & 909,6 & 338,9 & $1.248,6$ \\
\hline 1975 & $1.074,7$ & 600,1 & $1.674,8$ \\
\hline 1976 & $1.104,2$ & 899,0 & $2.003,2$ \\
\hline 1977 & $1.039,8$ & 522,2 & $1.562,0$ \\
\hline 1978 & $1.452,5$ & 690,7 & $2.143,1$ \\
\hline 1979 & $1.158,4$ & 564,7 & $1.723,1$ \\
\hline 1980 & $1.027,8$ & 288,4 & $1.316,3$ \\
\hline 1981 & 721,3 & 270,8 & 992,2 \\
\hline 1982 & 680,5 & 277,6 & 958,1 \\
\hline 1983 & 494,4 & 225,7 & 720,1 \\
\hline 1984 & 370,0 & 115,8 & 485,9 \\
\hline 1985 & 368,3 & 234,5 & 602,8 \\
\hline 1986 & 576,3 & 281,3 & 857,5 \\
\hline 1987 & 543,8 & 820,5 & $1.364,3$ \\
\hline 1988 & 499,8 & 372,9 & 872,7 \\
\hline 1989 & 312,7 & 86,1 & 398,8 \\
\hline 1990 & 216,0 & 21,1 & 237,1 \\
\hline 1991 & 104,2 & 69,0 & 173,2 \\
\hline 1992 & 153,5 & 445,3 & 598,8 \\
\hline 1993 & 263,9 & 699,4 & 963,3 \\
\hline 1994 & 590,3 & 533,0 & $1.123,2$ \\
\hline 1995 & 528,5 & 574,6 & $1.103,1$ \\
\hline 1996 & 617,5 & 598,2 & $1.215,6$ \\
\hline 1997 & 145,5 & $1.027,9$ & $1.173,3$ \\
\hline Total & $16.419,2$ & $11.078,3$ & $27.497,5$ \\
\hline Média & 586,4 & 357,4 & 887,0 \\
\hline
\end{tabular}

Fonte: FINEP. Elaboração do autor.

* Os anos com destaque são os que representam o auge e o início do descenso. 
científico nas instituições de pesquisa, sendo financiamentos não-reembolsáveis. Os recursos da FINEP referem-se ao financiamento para o investimento em inovação nas empresas, sendo reembolsáveis. A terceira linha (FINEP + FNDCT) representa a soma dos recursos ou a totalidade dos financiamentos para todo o processo de inovação.

Nota-se claramente pelos dados da Tabela 1, coluna FNDCT, que os anos de 1974 a 1980 foram os mais favoráveis ao financiamento da inovação.

No primeiro período é possível identificar três subperíodos de crescimento e queda dos financiamentos. O primeiro ocorreu de 1967 a 1984. Os financiamentos para a inovação cresceram até 1979. Em 1980 começou o período de queda. Os anos de 1976 a 1979 refletiram os investimentos do II Plano Nacional de Desenvolvimento (II PND) e foram aqueles de maior aplicação dos recursos do FNDCT e da FINEP. A partir de 1980 observa-se uma queda crescente até 1984. Nota-se que em 1981, como forma de diminuir a renúncia fiscal, os subsídios aos financiamentos foram cortados (Melo, 1988).

Os anos de queda acentuada dos financiamentos correspondem à crise econômica mundial decorrente do segundo aumento do preço do petróleo e da elevação unilateral da taxa de juros americana. O Brasil declara moratória em 1982, após o México, com vários países latino-americanos. Segue um período de aumento da inflação e recessão da economia de 1981 a 1983.

O segundo subperíodo, de 1985 a 1991, foi caracterizado pela redemocratização do país, pelo lançamento do Plano Cruzado em 1986 e pela nova moratória externa em 1987. A novidade em termos das fontes de financiamento foi a captação pela FINEP de recursos do Fundo Nacional de Desenvolvimento (FND). O FND havia sido criado durante a vigência do Plano Cruzado para financiar projetos de investimento de longo prazo. A fim de criar uma poupança forçada, taxaram-se extraordinariamente determinados produtos. Os consumidores desses produtos recebiam como contrapartida direitos futuros sobre as cotas do FND. Com o mecanismo, tentava-se controlar a explosão de demanda ocorrida com a estabilização de preços e aumento do poder aquisitivo da população. A partir do final de 1986 houve um rápido aumento da inflação, com forte instabilidade macroeconômica decorrente do fracasso do Plano Cruzado, a moratória em 1987 e o início do regime de alta inflação, que durou até 1994. Em 1989 ocorreu a primeira eleição direta no país depois de quase 30 anos. Em 1990 a crise se acentua e culmina com o desastre do Plano Collor I, caracterizado pelo sequestro da poupança corrente, que foi tomada como empréstimo pelo governo, para ser devolvida, anos mais tarde, aos detentores 
desses direitos. Nesse período a inflação voltou a disparar e alcançou níveis ainda mais altos, mostrando toda a desconfiança existente nos agentes econômicos a respeito da capacidade do governo em administrar a economia.

Nesse segundo subperíodo, os anos de 1985 a 1988 foram aqueles de crescimento dos financiamentos do FNDCT e da FINEP. Porém, mesmo com a criação do Ministério da Ciência e Tecnologia (MCT) em 1985, o qual supostamente deveria fortalecer a luta pelos recursos para aplicação em inovação, principalmente por meio do seu maior e mais flexível instrumento, o FNDCT, isso não ocorreu. A recuperação dos recursos foi tímida e praticamente não atingiu a metade dos recursos do auge do subperíodo anterior e, em 1990 e 1991, o FNDCT e a FINEP atingiram o mais baixo valor na aplicação de recursos.

Os anos do terceiro subperíodo, 1992 a 1997, foram marcados pelo regime econômico de alta inflação e a sua eliminação pelo lançamento do Plano Real em julho de 1994. Em 1993 ocorreu o impedimento do presidente Collor, sem que o país atravessasse uma crise política grave. Politicamente, esse fato representou um fortalecimento da democracia, porém na economia permanecia uma forte instabilidade macroeconômica decorrente da fragilidade externa e das altas taxas de inflação (Coutinho, 2005). O lançamento do Plano Real estabilizou as expectativas inflacionárias, mas para isso foi necessária uma elevação muito grande da taxa de juros, a valorização do real diante do dólar e a intensificação da abertura comercial iniciada no governo Collor.

A política econômica implementada no período 1994-1998 teve como objetivo central manter a inflação baixa e não permitir um novo surto de elevação dos preços. Baseada em uma elevada taxa de juros, forte valorização do real, abertura comercial e nova regulação dos mercados para atrair investimentos externos diretos ${ }^{9}$ e elevados deficits na balança comercial, tal política comercial terminou por aumentar a fragilidade financeira interna e externa pelo aumento explosivo das duas dívidas, fruto da combinação de altas taxas de juros e câmbio valorizado.

No terceiro subperíodo a FINEP conseguiu captar um empréstimo no BID, o que possibilitou desvincular o aumento dos recursos para o financiamento às empresas do crescimento dos recursos do FNDCT através de dotação orçamentária fiscal. Nesse período de recuperação do ciclo, foi agregada outra fonte de recursos: o Fundo de Amparo ao Trabalhador (FAT). A FINEP conseguiu captar recursos

\footnotetext{
9 A política de privatização foi uma política industrial implícita de modernização que alterou substancialmente a propriedade do capital das empresas nos setores de infraestrutura, e alguns, como telecomunicações, são de alto dinamismo tecnológico.
} 
desse fundo, que passou a constituir uma fonte quase permanente de recursos com o FND, para compor o funding da instituição para o financiamento do investimento nas empresas. O FNDCT iniciou uma recuperação em 1994, mas ela foi curta e voltou a cair em 1997. Os recursos orçamentários do FNDCT continuaram sem um expressivo aumento. Isso caracterizou esse subperíodo como aquele em que, pela primeira vez, os recursos aplicados pela FINEP superam os do FNDCT. Tal fato já apontava para a necessidade de reformular as fontes de recursos para o FNDCT, pelo esgotamento da capacidade fiscal do Estado brasileiro derivado da política de ajuste macroeconômico para a estabilização de preços.

\subsection{0 financiamento da inovação através dos fundos setoriais a partir de 1998}

A crise cambial de 1998-1999 acarretou uma mudança na política macroeconômica. A introdução do regime de metas de inflação e o objetivo de atingir superavit primário nas contas públicas, oriundo da aprovação da Lei de Responsabilidade Fiscal, exacerbaram o ambiente macroeconômico hostil para o investimento em inovação.

A relação entre a política macroeconômica e a formação de expectativas positivas para o investimento produtivo pode ser descrito pela seguinte afirmação: "[...] características específicas dos regimes macroeconômicos se sobrepõem e condicionam as decisōes microeconômicas, tendendo a conformar padrōes de financiamento e de governança corporativa, de comércio exterior, de concorrência e de mudança técnica" (Coutinho, 2005:430).

No contexto de uma política macroeconômica restritiva e com vistas a aproveitar a oportunidade surgida com a criação da Organização Mundial do Comércio (OMC), que permitiu o subsídio para as atividades de inovação, desenvolvimento regional e meio ambiente, passou a ser importante a definição de um conjunto de regras que definisse explicitamente a destinação de recursos públicos para o financiamento da inovação. Para a inovação, os critérios são mais amplos que os relativos ao desenvolvimento regional e meio ambiente. ${ }^{10}$ As normas da OMC admitem subsídios governamentais para o desenvolvimento tecnológico, mesmo quando específicos ou dirigidos diretamente à empresas, a aglomeraçóes de empresas e/ou setores produtivos. O apoio pode ser dado por transferência direta de fundos,

10 Os critérios de seleção para o financiamento do investimento em projetos de desenvolvimento regional e meio ambiente estão voltados para a adaptação de unidades industriais às exigências ambientais ou para o desenvolvimento de indústrias em regiões de baixa renda (renda per capita inferior a $85 \%$ da renda per capita nacional ou taxa de desemprego $10 \%$ superior à média do país). 
subvenções, créditos, financiamentos e participação no capital para as empresas, por meio de mecanismos de diminuição do risco como garantia de liquidez ou de crédito, incentivos fiscais e políticas de compras governamentais.

A solução encontrada para tentar eliminar a restrição fiscal foi a criação de contribuiçōes para fiscais, aproveitando a lacuna legal aberta com a aprovação da Contribuição Provisória sobre Movimentação Financeira (CPMF) e sua vinculação à área da saúde. ${ }^{11}$

Em 1997 surgiu o primeiro fundo para captação de recursos para a área de C\&T, a partir da vinculação de parcela dos royalties do petróleo. Em seguida, o Ministério da Ciência e Tecnologia iniciou estudos para a formulação de propostas a serem enviadas ao Congresso Nacional para a constituição de outros fundos setoriais. $\mathrm{O}$ início da operação dos fundos setoriais coincide com o auge da crise do balanço de pagamentos de $1998 .{ }^{12}$ A legislação que criou os fundos setoriais especificou vários itens. À exceção do fundo do petróleo, legalmente limitado à aplicação em instituições de ensino e pesquisa, os demais recursos poderiam ser aplicados em projetos de parceria (cooperativos) entre empresas e instituições de ensino e pesquisa e extensão sem fins lucrativos, desde que os recursos fossem destinados a estas últimas. Foi estabelecido legalmente um percentual mínimo que deveria ser destinado às regióes menos desenvolvidas, com o objetivo de reduzir as desigualdades regionais na geração e difusão das inovaçôes. Esse percentual era de $30 \%$ para as regiōes Norte, Nordeste e Centro-Oeste. Também nesse item o fundo do petróleo apresentava diferenças, uma vez que destinava $40 \%$ dos recursos para as regiôes Norte e Nordeste.

A legislação também definiu diretrizes gerais para a operação dos fundos setoriais, sendo:

1) modernizar e ampliar a infra-estrutura de $C \& T$;

2) promover maior sinergia entre universidades, centros de pesquisa e setor produtivo;

3) criar novos incentivos ao investimento privado em C\&T;

4) incentivar a geração de conhecimento e inovações que contribuam para a solução dos grandes problemas nacionais;

11 A criação dos fundos setoriais está descrita e analisada em detalhes em Bastos (2003).

12 Período marcado por uma forte instabilidade econômica que gerou uma alta volatilidade nos mercados financeiros internos, que tinham sido desregulamentados e estavam estreitamente associados aos movimentos dos fluxos internacionais de capitais. 
5) estimular a articulação entre ciência e desenvolvimento tecnológico, com a redução das desigualdades regionais e a interação entre universidades e empresas. $^{13}$

Com exceção do Fundo para o Desenvolvimento Tecnológico das Telecomunicações (FUNTTEL), gerido pelo Ministério das Comunicações, os recursos dos demais fundos são alocados no FNDCT e administrados pela FINEP, como sua Secretaria Executiva. Essa é a única semelhança entre o modelo de gestão anterior e o atual. $\mathrm{O}$ modelo de gestão conceBIDo para os fundos setoriais é baseado na existência de comitês gestores, um para cada fundo. Cada comitê gestor é presidido por um representante do MCT e integrado por representantes dos ministérios afins, agências reguladoras, setores acadêmicos e empresariais, bem como das agências do MCT, da FINEP e do Conselho Nacional de Desenvolvimento Científico e Tecnológico (CNPq). Os comitês gestores têm a prerrogativa legal de definir as diretrizes, as açôes e os planos de investimentos dos fundos, respeitadas as diretrizes gerais apresentadas anteriormente.

A ausência de um comitê gestor geral levou à criação em 2004 do Comitê de Coordenação dos Fundos Setoriais, com o objetivo de integrar suas ações. O comitê é formado pelos presidentes dos comitês gestores, pelos presidentes da FINEP e do CNPq, sendo presidido pelo ministro da Ciência e Tecnologia.

O Decreto n.4.195, de 11/4/2002, regulamentou a Lei n.10.168, de 29/12/2000, que instituiu a contribuição de intervenção no domínio econômico destinada a financiar o Programa de Estímulo à Interação Universidade-Empresa para Apoio à Inovação. Já a Lei n.10.332, de 19/12/2001, institui mecanismos de financiamento para programas de C\&T. No artigo 2º, os instrumentos são definidos da seguinte forma:

"1. equalização dos encargos financeiros incidentes nas operaçôes de financiamento à inovação tecnológica, com recursos da FINEP;

2. participação minoritária no capital de MPEs de base tecnológica e fundos de investimento;

3. constituição, por intermédio da FINEP, de reserva técnica para viabilizar a liquidez dos investimentos privados em fundos de investimento em empresas de base tecnológica;

4. subvenção com recursos do Fundo Verde Amarelo - FVA".

$13 \mathrm{~A}$ especificação detalhada de toda a legislação dos fundos setoriais pode ser encontrada em <http://www.mct.gov. $\mathrm{br} /$ Fontes/Fundos/Default.htm>. 
Posteriormente, em 2002, uma portaria do ministro de Ciência e Tecnologia criou a linha de liquidez para investimentos em empresas de base tecnológica, ou seja, nas que se enquadram na Instrução CVM n.209/94 e CVM n.391/2002 da Comissão de Valores Mobiliários (CVM). Pela atual legislação, apenas o Fundo Verde e Amarelo $\left(\mathrm{FVA}^{14}\right)$ está autorizado a fazer o aporte financeiro direto nas empresas, inclusive por via de capital de risco. A alocação de recursos para esses instrumentos tem sido muito precária, conforme é possível constatar na Tabela 2, que apresenta os valores consignados em lei de 2002.

Pode-se dizer que o FVA procura suprir uma deficiência na operação dos demais fundos setoriais, definindo explicitamente mecanismos para o financiamento direto das empresas. No padrão anterior, o programa ADTEN procurava preencher essa lacuna. Porém a destinação dos recursos até o ano de 2005 foi muito pequena, conforme pode ser visto na Tabela 3.

A Tabela 3 apresenta a evolução dos desembolsos do FNDCT e da FINEP no período de vigência dos fundos setoriais. Na FINEP foi mantida a captação de recursos do FAT e do FND. A aplicação dos recursos do FNDCT apresenta uma tendência de crescimento até 2006. Os recursos para o financiamento das empresas só apresentam aumento expressivo a partir de 2005.

A política operacional dos recursos do FNDCT oriundos dos fundos setoriais, que é a parte amplamente majoritária, não é mais definida pela FINEP..$^{15} \mathrm{~A}$ forma de aplicação desses recursos são os projetos cooperativos, refletindo a definição política de priorizar os recursos destinados às instituições de pesquisa por meio dos projetos, entre elas e as empresas. As prioridades são definidas pelos comitês gestores de cada fundo setorial.

Esse conjunto de novas normas operacionais, mais restritivas, impediu que a FINEP pudesse repassar os recursos do FNDCT, como fazia no período anterior, para o financiamento das empresas. $\mathrm{O}$ argumento de impedimento legal para isso não existe agora, como não existiu antes. Ele reflete uma nova concepção de política de inovação, que privilegia os projetos cooperativos como forma prioritária de incentivo para as empresas inovarem. Tal política não encontra respaldo em nenhuma experiência histórica, e creio que não encontrará no Brasil. Nos Estados Unidos,

\footnotetext{
14 O Fundo Nacional de Telecomunicações (FUNTEL) também está autorizado legalmente a destinar recursos diretamente para o aporte financeiro nas empresas.

15 Os recursos do orçamento fiscal para o FNDCT, denominados Fonte 100, que eram os que o alimentavam no primeiro período, praticamente passaram a ser marginais após a consolidação dos fundos setoriais. Eles respondem no segundo período por menos de $10 \%$ em média do montante dos recursos dos fundos setoriais, <www.mct.gov. br e www.finep.gov.br>.
} 
TABELA 2

Recursos aprovados por lei, 2002-2005 (em R\$ mil correntes)

\begin{tabular}{|c|c|c|c|c|c|}
\hline Instrumentos - FVA & 2002 & 2003 & 2004 & 2005 & Total \\
\hline Equalização & $8.400,00$ & $35.064,94$ & $29.330,00$ & $40.900,00$ & $113.694,94$ \\
\hline Participação no capital & $5.000,00$ & $21.038,96$ & $17.600,00$ & $17.588,00$ & $61.226,96$ \\
\hline Garantia de liquidez & 0,00 & 0,00 & $5.300,00$ & $2.000,00$ & $7.300,00$ \\
\hline Total & $13.400,00$ & $56.103,90$ & $52.230,00$ & $62.493,00$ & $184.226,90$ \\
\hline
\end{tabular}

Fonte: Sistema Integrado de Administração Financeira do Governo Federal (SIAFI) e MCT.

TABELA 3

Evolução dos desembolsos da FINEP e do FNDCT, 1998-2006

(em R\$ milhões constantes de média anual IPCA - dez. 2006)

\begin{tabular}{cccc}
\hline Ano & FNDCT & FINEP & FINEP + FNDCT \\
1998 & 165,7 & 856,6 & $1.022,4$ \\
1999 & 192,2 & 396,0 & 588,2 \\
2000 & 263,9 & 223,0 & 486,8 \\
2001 & 590,3 & 140,3 & 730,6 \\
2002 & 528,5 & 170,7 & 699,3 \\
2003 & 617,5 & 166,5 & 783,9 \\
2004 & 716,3 & 166,5 & 882,8 \\
2005 & 797,9 & 322,3 & $1.120,2$ \\
2006 & 787,3 & 515,9 & $1.303,1$ \\
Total & $4.659,5$ & $2.957,7$ & $7.617,2$ \\
\hline
\end{tabular}

Fonte: FINEP. Elaboração do autor. 
maior produtor de ciência do mundo e com um setor produtivo de altíssima capacidade de inovação, onde esses arranjos cooperativos vêm sendo incentivados desde a década de 1980, apenas $7 \%$ das atividades de pesquisa de universidades foram provenientes de contratos com empresas e menos de $5 \%$ das 85 mil patentes em 2000 foram efetuados por universidades (Bastos, 2003).

A política macroeconômica restritiva também atuou para impedir um melhor desempenho da FINEP e do FNDCT no segundo período. Os incentivos para o crescimento econômico vieram do setor externo, estimulado pela forte desvalorização cambial de 1999-2000 e de 2002-2003 e, principalmente, pelo fator China, com forte aumento do preço internacional das commodities. Mesmo com a redução da fragilidade externa da economia, a política monetária continuou extremamente tímida na redução das taxas de juros, o que fez com que o ambiente macroeconômico hostil perdurasse, resultando em baixo investimento das empresas brasileiras. Com exceção das grandes empresas que estão investindo no exterior (Lessa, 2007), as demais praticamente se encontram estagnadas. Isso é mais grave ainda do que em outros períodos, porque a valorização tem levado à desestruturação das cadeias produtivas internas e dos arranjos e configuraçóes produtivas locais, em especial aquelas predominantemente constituídas por micro e pequenas empresas.

Em 2006 foi aprovada a regulamentação dos recursos para subvenção, baseada na Lei de Inovação (Lei n.10.973, de 2/12/2004) e na denominada Lei do Bem, Lei n.11.196, de 21/11/2005. Com isso, o MCT e a FINEP iniciavam a operação desse instrumento.

Os fundos setoriais foram formulados como uma alternativa ao financiamento do investimento em inovação das empresas nacionais e para enfrentar a deterioração da infraestrutura nas instituiçôes de pesquisa científica e tecnológica. Mesmo que o legislador da época tenha procurado se precaver contra os requisitos da política de superavits primários a todo custo, na operação sempre prevaleceu a maior força política do Ministério da Fazenda. Bastos explicita claramente as razões que levaram à criação desses mecanismos de preservação dos recursos dos fundos setoriais que na prática não surtiram efeito:

"O sucesso das açôes dependia, ainda, da Medida Provisória 2.010-30, de 28.03.00, com vistas a desobrigar a devolução ao Tesouro Nacional, no final de cada exercício, de recursos existentes em caixa do FNDCT. A medida visava permitir que passasse a operar como fundo efetivo, não mais atrelado à execução anual do Orçamento, mas com uma gestão plurianual. Quando da sua conversão, após sucessivas reediçôes, na 
Lei 10.148, de 21.12.00, o FNDCT foi excluido do conjunto de fundos que estariam desobrigados a recolher superávits financeiros ao Tesouro Nacional, excepcionalizados dos efeitos da Lei 9.530, de 10.12.97 (que determinou o recolhimento). O problema foi contornado pela inclusão no texto das leis de alguns 'fundos' setoriais (energia, espacial, recursos hidricos e minerais, transportes terrestres, verde e amarelo) de um dispositivo que garantia a manutenção dos superávits apurados em final de exercício no FNDCT e no Funttel. Nos demais 'fundos' (petróleo, infra-estrutura e informática) não há, contudo, essa alteração, o que significa, pela lei, que superávits de final de exercício continuaram obrigados a ser recolhidos ao Tesouro". (2003:236)

O contingenciamento dos recursos do FNDCT vem sendo feito de forma crescente, como pode ser observado na Tabela 4. Atualmente existem mais recursos contingenciados do que aqueles que foram colocados à disposição do FNDCT para o financiamento da inovação e da infraestrutura de C\&T. É uma forte contradição entre a política macroeconômica e a Política Industrial de Tecnologia e de Comércio Exterior - PITCE, políticas estas que explicitam objetivos incompatíveis entre si.

Interessante é observar a evolução dos fundos criados para o apoio ao financiamento e à difusão da inovação na área de telecomunicações. É de notório saber que essa é uma área altamente sensível para a capacitação tecnológica de um país. Porém nota-se que este não deve ser o entendimento do Ministério da Fazenda. Os dados apresentados na Tabela 5 mostram que o Fundo para Universalização das Telecomunicações (FUST) não foi aplicado. O Fundo de Fiscalização das Telecomunicaçōes (FISTEL) teve 10\% dos seus recursos aplicados e o FUNTTEL, 50\%. Ao que parece, o contingenciamento é regra, e não a exceção.

\subsection{Capital de risco ${ }^{16}$ e novos programas}

Uma das características importantes do segundo período foi a volta da preocupação com os instrumentos de participação no capital das empresas, que haviam sido abandonados desde meados da década de 1980, em virtude da alta volatilidade do mercado de capitais brasileiro, decorrente da crise do balanço de pagamentos, da recessão econômica e do corte do financiamento externo derivados da moratória do México.

16 A FINEP já tinha experiência com investimento de participação no risco nas empresas no final da década de 1970 e início da década de 1980 (Melo, 1988). 
TABELA 4

Evolução financeira do FNDCT, 1998-2006 (em R\$ milhões constantes de média anual IPCA - dez. 2006)

\begin{tabular}{cccc}
\hline Ano & Valores aplicados & Arrecadação & Contingenciamento \\
1998 & 165,7 & 165,7 & 0,0 \\
1999 & 192,2 & 224,8 & 32,6 \\
2000 & 263,9 & 453,8 & 189,9 \\
2001 & 590,3 & 773,4 & 183,1 \\
2002 & 528,5 & $1.358,1$ & 829,6 \\
2003 & 617,5 & $1.550,6$ & 933,1 \\
2004 & 716,3 & $1.551,7$ & 835,4 \\
2005 & 797,9 & $1.743,8$ & 945,9 \\
2006 & 787,3 & $1.850,4$ & $1.063,1$ \\
Total & $4.659,5$ & $9.672,2$ & $5.012,7$ \\
\hline
\end{tabular}

Fonte: FINEP, SIAFI e MCT. Elaboração do autor.

A FINEP criou no ano 2000 o programa INOVAR, ${ }^{17}$ o qual consiste de uma série de atividades voltadas para a capacitação de micro e pequenas empresas (MPEs) inovadoras, que desejem participar de programas de investimento com participação no risco. O projeto INOVAR é constituído por seis programas integrados, sendo: Fórum Brasil Capital de Risco, Incubadora de Fundos INOVAR, Fórum Brasil de Inovação, Portal Capital de Risco Brasil, Rede INOVAR de Prospecção e Desenvolvimento de Negócios, Desenvolvimento de Programas de Capacitação e Treinamento de Agentes de Capital de Risco. A Incubadora de Fundos INOVAR é uma realização conjunta da FINEP, do Fundo Multilateral de Investimentos do Banco Interamericano de Desenvolvimento (FUMIN/BID), do Serviço Brasileiro de Apoio às Micro e Pequenas Empresas (SEBRAE), do Banco do Brasil Investimentos (BB-BI), da Bolsa de Valores de São Paulo (BOVESPA) e dos fundos de pensão dos funcionários do Banco do Brasil (PREVI), da Petrobras (PETROS) e da Caixa Econômica Federal (FUNCEF).

17 Para informações do programa INOVAR, ver site da FINEP, <WwW.FINEP.gov.br>. 
TABELA 5

Arrecadação dos fundos de telecomunicações, 2001-2005

(em R\$ bilhões correntes)

\begin{tabular}{lcccccccc}
\hline Fundo/Ano & 2001 & 2002 & 2003 & 2004 & 2005 & Total & Investimento & $\%$ investido \\
FUST & 1,0 & 1,1 & 0,5 & 0,7 & 0,6 & 3,9 & 0 & $0 \%$ \\
FUNTTEL & 0,1 & 0,2 & 0,2 & 0,2 & 0,3 & 1,0 & 0,5 & $50 \%$ \\
FISTEL & 4,4 & 2,7 & 1,3 & 2,0 & 2,1 & 12,5 & 1,3 & $10 \%$ \\
Total & 5,5 & 4,0 & 2,0 & 2,9 & 3,0 & 17,4 & 1,8 & $10,06 \%$ \\
\hline
\end{tabular}

Fonte: ANATEL e Tesouro Nacional.

Em dezembro de 2005, a FINEP lançou o programa INOVAR Semente, para apoiar empresas nascentes, isto é, financiamento para o investimento no capital de empresas em um estágio pré-operacional. Pode-se dizer que o programa INOVAR foi das inovaçôes financeiras mais importantes já implantadas no âmbito do sistema de financiamento à inovação no Brasil. Porém, mais uma vez, mesmo tendo antecipado uma tendência que só agora se está concretizando no mercado de capitais, o INOVAR sofre com o contingenciamento dos recursos do FVA e com a timidez da FINEP em estabelecer uma atuação mais direta na área de financiamento por via de participação no risco das empresas inovadoras.

Essa posição tímida parece desconsiderar a mudança ocorrida na posição do mercado de capitais no Brasil. A partir de 2005, conforme se observa no Gráfico 1, houve uma grande busca de financiamento por via de mercado de capitais. Tal movimento das empresas representava uma alteração positiva nas suas expectativas de investimento, o que já denotava uma maior confiança nos retornos desses investimentos. Isso reforça a percepção de que uma política monetária menos restritiva, que tornasse mais baixa a taxa de juros e mais alta a taxa de câmbio, teria conduzido as empresas brasileiras a uma estratégia de investimento mais dinâmica e, possivelmente, com melhorias na geração de inovações.

O programa Juro Zero foi lançado pela FINEP em 2005 e começou a operar em 2006. Sua principal característica é reduzir o custo do financiamento e fixar a amortização do principal em cem parcelas. Outro objetivo é reduzir a burocracia no pedido dos financiamentos. $\mathrm{O}$ foco do programa são as empresas inovadoras com 
GRÁFICO 1

Captação por via de mercado de capitais - 1996-2006 (R\$ bilhões)

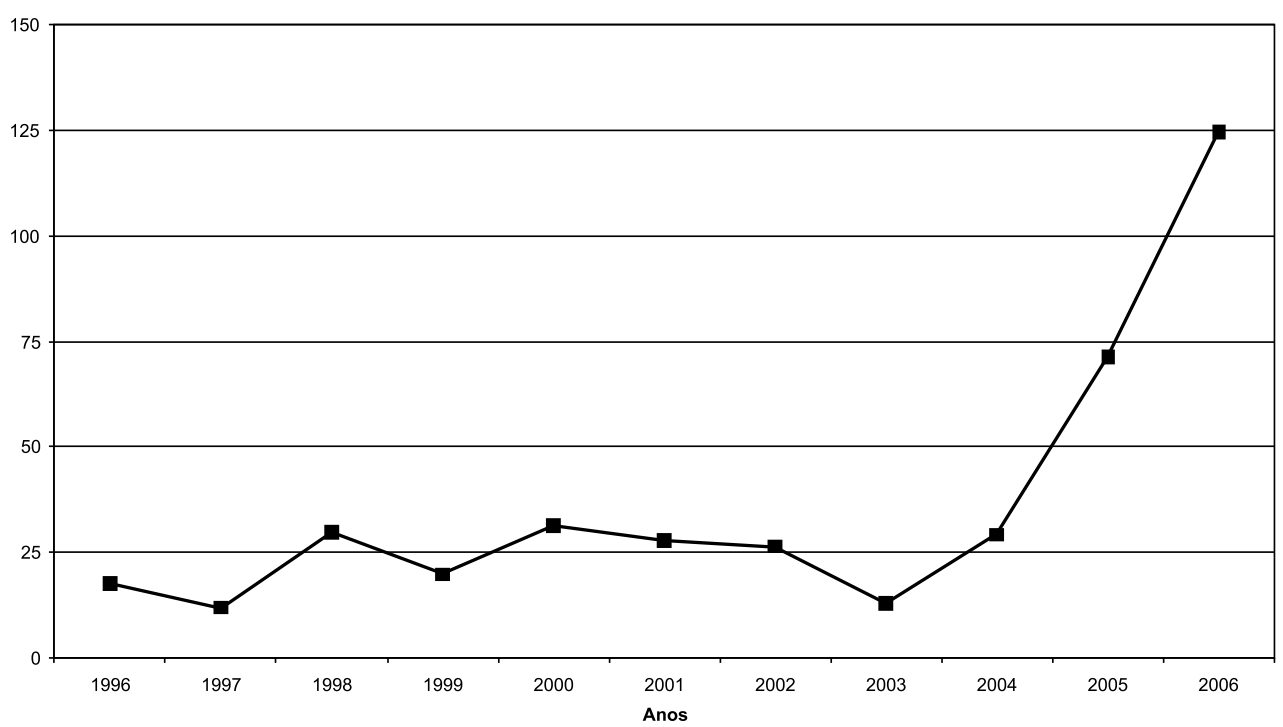

Fonte: Comissão de Valores Mobiliários (CVM). Elaboração do autor.

faturamento anual de até $\mathrm{R} \$ 10,5$ milhões. Os valores dos financiamentos variam de R\$ 100 mil a R\$ 900 mil, corrigidos apenas pelo índice da inflação (Índice de Preços ao Consumidor Amplo - IPCA). Não há carência, portanto a empresa tomadora do financiamento tem de pagá-lo no mês seguinte à liberação do empréstimo. Para tornar mais ágil a concessão dos financiamentos, a FINEP está treinando parceiros locais para a pré-qualificação das propostas e sua aprovação e vai credenciá-los por meio de convênios. Após a pré-qualificação, as propostas serão enviadas à financiadora para a aprovação final e contratação.

O programa Juro Zero não pede garantias reais formais para as MPEs. Especifica uma reserva de recursos financeiros para garantir o financiamento. Inicialmente, os sócios da empresa proponente oferecem uma fiança de $20 \%$ do valor total do financiamento. Em seguida, é feito um desconto antecipado de 3\% de cada empréstimo para a criação de um fundo de reserva correspondente a $30 \%$ do total do financiamento. Essa taxa retornará para as empresas após a quitação do financiamento, caso não haja inadimplência, corrigida pelo IPCA. Para serem credenciados, os agentes locais terão de criar um Fundo de Garantia de Crédito correspondente ao valor dos $50 \%$ restantes. 
TABELA 6

Comparação entre as médias de desembolsos do FNDCT e da FINEP nos dois períodos

Média 1967-1997 (FINEP)

e 1970-1997 (FNDCT) (A)
Média 1998-2006 (B)

517,7
(A) / (B)

$13,27 \%$
FNDCT

FINEP
586,4

357,4

\subsection{Comparação entre os períodos}

Na Tabela 6 apresenta-se a média dos financiamentos concedidos pela FINEP e pelo FNDCT nos dois períodos. O primeiro período teve um valor médio dos financiamentos não-reembolsáveis, FNDCT, e dos financiamentos reembolsáveis, FINEP, superior aos do segundo período.

O primeiro ponto a ser considerado para explicar a média superior dos desembolsos no primeiro período, do FNDCT e da FINEP, foi a maior compatibilidade entre a política macroeconômica e a política de inovação, na década de 1970. É importante lembrar a ênfase que era dada ao planejamento e, em decorrência, a articulação entre os Planos Básicos de Desenvolvimento Científico e Tecnológico (PBDCT) e os Planos Nacionais de Desenvolvimento (PND) que vigoraram no período.

Nas décadas de 1980 e 1990, essa compatibilidade entra em crise. Porém, de modo intermitente, existem subperíodos de recuperação. A queda dos recursos do FNDCT nas décadas de 1980 e 1990 foi compensada com a captação de novas fontes de financiamento reembolsável pela FINEP. Note-se, Tabelas 1 e 3, que os anos de maior desembolso da FINEP em financiamentos reembolsáveis foram os de 1976, 1987, 1997 e 1998. Os dois últimos em decorrência de um empréstimo do BID. O primeiro no auge do II PND, e 1987 devido ao empréstimo do FND. O que ocorre é uma tendência de queda do FNDCT não-reembolsável a partir do final da década de 1980. 
As médias menores no segundo período decorreram diretamente da política de ajuste fiscal muito restritiva, conforme mostrado nas Tabelas 4 e 5 . Caso a política tivesse sido menos restritiva, a média dos recursos para aplicação em financiamento reembolsável teria sido maior. Isso mostra uma incompatibilidade entre a política macroeconômica e a política de inovação, isto é, uma intervenção do Estado com menor consistência e coerência, como recomenda o conceito de sistema nacional de inovação, pelo menos quando comparada com a década de 1970.

"As pesquisas sobre o comportamento tecnológico das empresas brasileiras hoje disponiveis, dentre as quais a PINTEC/IBGE, agora em sua terceira edição, tornaram possivel a compreensão de quanto, como e onde a empresa brasileira inova. Por meio desses estudos foi possivel aprender que a inovação depende do setor de atividade, do tamanho da empresa, da origem do capital controlador e, fundamentalmente, da natureza dos arranjos institucionais especificos presentes (ou ausentes) ligandoos entre si e também com as politicas públicas e a infra-estrutura cientifica e tecnológica disponivel." (Kupfer, 2007)

O segundo ponto a ser considerado na comparação dos dois períodos, que decorre da citação acima, é a explícita prioridade do programa ADTEN para o financiamento da empresa nacional. Se o que importa para a inovação é a criação de conhecimento tácito e a constituição de ativos intangíveis, a questão da origem do capital é crucial. As empresas com maioria do capital nacional devem ser priorizadas.

O terceiro ponto a ser levado em conta é a modernização dos instrumentos financeiros. O primeiro período foi quase todo dominado pela concessão de crédito subsidiado sobre a correção monetária, que era altíssima. Isso fazia com que os financiamentos se tornassem mais atrativos do que a participação no capital das empresas. No contexto de um regime macroeconômico de baixa inflação, sem indexação de ativos e preços, de queda da taxa de juros e de fortalecimento do mercado de capitais, o financiamento do investimento em inovação deve ser realizado, de forma integrada, por instrumentos de participação, por crédito com taxas de juros equalizados e pela concessão de subvenção. A lógica dessa atuação integrada é a constituição de empresas inovadoras nacionais fortes, com escala e estrutura de capital capaz de evitar a fragilidade financeira. 


\section{Conclusão}

A primeira grande diferença entre os dois períodos reside no contexto internacional. A grande mudança de política internacional que ocorreu na década de 1980 com a hegemonia do pensamento neoliberal, orientando as políticas econômicas na direção de maior liberalização comercial e da conta de capital do balanço de pagamentos, taxas de câmbio flexíveis, ajuste fiscal e controle da inflação. A maioria dessas políticas estava em contraposição à política de desenvolvimento econômico dominante por quase todo o primeiro período, caracterizada pelo que se convencionou chamar de modelo de substituição de importações. No Brasil, essas políticas começaram a ser adotadas no governo Collor e foram mantidas pelos governos seguintes, em especial na orientação da política macroeconômica. ${ }^{18}$

É claro que essa diferença no contexto internacional, mas não somente ela, levou a uma mudança nas prioridades de aplicação dos recursos e nas fontes de recursos do FNDCT e da FINEP. No primeiro período existia uma preocupação explícita no documento do programa ADTEN com o apoio às empresas nacionais (maioria da propriedade do capital brasileiro), bem como uma maior coordenação entre a aplicação dos recursos do FNDCT e da FINEP, até pelo fato de a FINEP ser praticamente a definidora da estratégia operacional dos dois.

A fonte de recursos do FNDCT era, majoritariamente, o orçamento fiscal. O FNDCT era um fundo de livre aplicação; repassava recursos para a FINEP financiar as empresas e, em alguns períodos, era complementado por financiamentos externos (Melo, 1988, 1994). ${ }^{19}$

No segundo período deixa de existir exclusividade para as empresas de capital nacional. A FINEP perde quase toda a sua autonomia na definição da estratégia da aplicação dos recursos do FNDCT através dos fundos setoriais. Atualmente cada fundo setorial tem um comitê gestor e existe um comitê gestor geral do FNDCT, no qual a FINEP é minoritária. A estratégia está muito mais nas mãos do MCT do que nas da FINEP.

18 Uma discussão abrangente das mudanças no contexto mundial que cobre todo o período em análise pode ser encontrada em Fiori (2004). No que se refere às mudanças de política econômica e à comparação do desempenho dos países que adotaram as políticas liberalizantes e os que resistiram a elas, ver Rodrik (2007).

19 Em 1984 o governo brasileiro assinou um contrato com o Banco Mundial para o Programa de Apoio ao Desenvolvimento Científico e Tecnológico (PADCT). O funding desse programa seria composto por um empréstimo do Banco Mundial e contrapartida do FNDCT. O impacto dos recursos do programa foi muito pequeno, não atingindo $5 \%$ dos recursos totais gerenciados pela FINEP. A sua maior marca foi o novo modelo gerencial dos seus recursos e aplicações através dos comitês assessores, o qual viria a ser a base para o modelo gerencial dos fundos setoriais (Bastos, 2003; Milanez, 2007). 
Porém alguns avanços foram realizados com a criação dos fundos setoriais. Em primeiro, conforme apresentado nas Tabelas 4 e 5, havendo uma mudança na direção de uma política macroeconômica mais favorável ao crescimento econômico, com menor restrição fiscal e contingenciamento dos recursos, haverá um salto na disponibilidade de recursos para os fundos setoriais.

Em segundo, o programa INOVAR poderá constituir-se em uma forte fonte de indução ao investimento em inovação, desde que a FINEP tenha uma estratégia de atuação mais agressiva, integrando-o com a subvenção e a equalização da taxa de juros dos financiamentos concedidos e com a subvenção. Também será necessário algum tipo de controle sobre a venda das empresas de base tecnológica que fazem parte da carteira dos fundos de capital de risco da Incubadora de Fundos INOVAR, a fim de evitar que a promoção das firmas nacionais se acabe tornando um incentivo fiscal indireto para investidores estrangeiros e o país acabe pagando dividendos, royalties, licenças e outras rendas para tecnologias desenvolvidas com os recursos nacionais e perca essa capacitação empresarial para a inovação.

Para isso os fundos setoriais podem ser decisivos, desde que vencida a barreira da política monetária restritiva, com a eliminação do contingenciamento de recursos, e assim possibilitando uma maior disponibilidade financeira para o financiamento da inovação. Porém, se o objetivo é avançar na constituição de instrumentos financeiros voltados para a avaliação de ativos intangíveis e para a formação de empresas nacionais inovadoras, será fundamental o avanço na definição de um seguro de garantia de crédito e de garantia de liquidez para os investimentos em inovação. O primeiro para garantir o risco do financiamento; o segundo para garantir o investimento em participação, a titularidade dos ativos e a securitização das dívidas. A securitização aumenta a competição por recursos entre as instituições do sistema financeiro, reduz o poder dos bancos, diminui os spreads extorsivos e fortalece o mercado de capitais e aumenta a disponibilidade de crédito.

Em resumo, é importante o aumento dos recursos para o aporte financeiro, participação, equalização, subvenção e garantia de crédito e liquidez com a respectiva redução e eliminação do contingenciamento de recursos. A FINEP precisará se capacitar para operar todas as formas de participação no risco nas empresas inovadoras. Hoje está restrita, quase que exclusivamente, à participação em fundos de capital de risco para empresas emergentes de base tecnológica. É uma forma indireta, talvez menos arriscada, mas não condiz com o papel institucional estratégico que uma instituição financeira pública deve ter na criação dessas empresas e no compartilhamento do risco do investimento em inovação. 


\section{Referências bibliográficas}

Albuquerque, E.M. Apresentação de "The National System of Innovation in historical perspective”, Revista Brasileira de Inovação, Rio de Janeiro, v.3, n.1, p.9-13, jan.-jun., 2004.

Bastos, V.D. Revista do BNDES, Rio de Janeiro, v.10, n.20, p.229-260, dez., 2003.

Brito, J. et al. "Formatos organizacionais para financiamentos de arranjos e sistemas de MPME”, Nota Técnica 1.9 no âmbito da pesquisa Proposição de Políticas para a promoção de sistemas produtivos locais de micro, pequenas e médias empresas, out., 2001. Disponível em <www.redesist.ie.ufrj.br>.

Carvalho, F.J.C. "Sistema financeiro, crescimento e inclusão", Seminário Brasil em Desenvolvimento, Rio de Janeiro, IE-UFRJ, mimeo., 2003.

CGEE. Capital de risco no Brasil: marco legal e experiência internacional, Brasília: CGEE, 2003a.

. Capital de risco no Brasil e desenvolvimento tecnológico no Brasil, Brasília: CGEE, 2003b.

Chandler, A.D. Scale and scope: the dynamics of industrial capitalism, Cambridge (MA): Harvard University Press, 1990.

Chang, H. Chutando a escada: a estratégia do desenvolvimento em perspectiva histórica, São Paulo: Editora UNESP, 2004.

Chesnais, F.; Sauviat, C. "O financiamento da inovação no regime global de acumulação dominado pelo capital financeiro", in Lastres, H.M.; Cassiolato, J.E.; Arroio, A. (eds.), Conhecimento, sistemas de inovação e desenvolvimento, Rio de Janeiro: Editora UFRJ, Contraponto, 2005.

Christensen, J. "The role of finance in National Systems of Innovation", in Lundvall, L.B. (ed.), National Systems of Innovation: towards a theory of innovation and interactive learning, Londres: Frances Pinter, 1992.

Corder, S.; Salles-Filho, S. "Aspectos conceituais do financiamento da inovação", Revista Brasileira de Inovação, Rio de Janeiro, v.5, n.1, p.33-76, jan.-jul., 2006.

Coutinho, L.G. "Regimes macroeconômicos e estratégias de negócio: uma política industrial alternativa para o Brasil no século XXI", in Lastres, H.M.; Cassiolato, J.E.; Arroio, A. (ed.), Conhecimento, sistemas de inovação e desenvolvimento, Rio de Janeiro: Editora UFRJ, Contraponto, 2005. 
Dosi, G. "Finance, innovation, and industrial change", Journal of Economic Behavior and Organization, v.13, p.299-329, 1990.

Erber, F. "O sistema de inovações em uma economia monetária - Uma agenda de pesquisas”, in Cassiolato, J.E.; Lastres, H.M.M. (eds.), Globalização e inovação localizada: experiências de sistemas locais no Mercosul, Brasília: CNPq/IBICT, 1999.

Exposição de Motivos - EM n.252, de 31 de agosto de 1976, do ministro do Planejamento para o presidente da República, Brasília, Ministério do Planejamento, 1976.

Fiori, J.L. (org.) O poder americano, Petrópolis: Vozes, 2004.

Freeman, C. Technology policy and economic performance: lessons from Japan, Londres: Frances Pinter, 1987.

. "The economics of technical change", Cambridge Journal of Economics, v.18, n.5, p.463-518, 1994.

. "The 'National System of Innovation' in historical perspective", Cambridge Journal of Economics, v.19, n.1, p.5-24, 1995.

Freeman, C.; Perez, C. "Structural crisis of adjustment: business cycles and investmente behaviour”, in Dosi, G.; Freeman, C.; Silverberg, G.; Soete, L. (eds.), Technical change and economic theory, Londres: Frances Pinter, p.38-66, 1988.

Guimarães, E.A. "Políticas de inovação: financiamento e incentivos”, Texto para Discussão, Brasília: IPEA, n.1.212, ago., 2006.

Kupfer, D. "Desafios profundos”, Valor Econômico, 14/11/2007.

Lessa, C. "A opção pelos pobres e a crítica de Delfim Netto", Valor Econômico, $14 / 2 / 2007$.

Levine, R.; Zervos, S. “Stock markets, banks, and economic growth”, The American Economic Review, v.88, n.3, p.537-558, 1998.

Lundvall B.A. (ed.) "National Systems of Innovation: towards a theory of innovation and interactive learning, Londres: Frances Pinter, 1992.

Mayer, C. "Myths of the West: lessons from developed countries for development finance", World Bank Discussion Paper and Background Paper for the 1989 World Bank Development Report, 1989.

"The financing and governance of new technologies", paper prepared for the UN University/EU DG Research Conference on Financial Systems, Corporate Investment in Innovation and Venture Capital in Brussels on 7-8 November 2002, University of Oxford, 26 out., 2002. 
Melo, L.M. de. "O financiamento ao desenvolvimento científico e tecnológico: a experiência da FINEP - 1967 a 1988”, Dissertação de Mestrado, Rio de Janeiro, Instituto de Economia da UFRJ, 1988.

. "O financiamento da inovação industrial", Tese de Doutorado, Rio de Janeiro, Instituto de Economia da UFRJ, 1994.

. "Sistema Nacional de Inovação (SNI): uma proposta de abordagem teórica”, Texto para Discussão, IE-UFRJ, n.357, abr., 1996.

"Inovação, financiamento e sistemas locais de produção", Anais do First Globelics Conference: Innovation Systems and Development Strategies for the Third Millenium, Rio de Janeiro, 2003.

Milanez, A.Y. "Os fundos setoriais são instituições adequadas para promover o desenvolvimento industrial do Brasil?", Revista do BNDES, Rio de Janeiro, v.14, n.27, p.123140, jun., 2007.

Minsky, H.P. "The financial-instability hypothesis: capitalist processes and the behaviour of the economy”, in Kindleberger, C.P.; Lafargue, J.P., Financial crises, Cambridge: Cambridge University Press, 1982.

Miranda, J.C.; Tavares, M.C. "Brasil: estratégias de conglomeração", in Fiori, J.L. (org.), Estados e moedas no desenvolvimento das naçōes, Petrópolis: Vozes, 1999.

Mytelka A.L. "Uma nova iniciativa para fortalecer as economias locais: o Banco de Arranjos Produtivos", in Lastres, H.M.M. et al. (coord.), Interagir para competir: promoção de arranjos produtivos e inovativos no Brasil, Brasília: SEBRAE, FINEP, CNPq, 2002.

Nelson, E.R. (ed.) National Innovation Systems: a comparative analysis, Oxford: Oxford University Press, 1993.

OECD - Organization Economic Cooperation and Development. Venture capital and innovation, Paris: OECD, 1996. Disponível em <http://www.OECD.org>.

O'Sullivan, M. "Finance and innovation", in Fagerberg, J.; Mowery, D.C.; Nelson, R.C. (org.), The Oxford handbook of innovation, Oxford: Oxford University Press, 2005.

Patel, P.; Pavitt, K. "The nature and economic importance of National Innovation Systems”, STI Review, n.14, p.9-32, 1994.

Paula, J.A. et al. "Finance and industrial relationship: introductory notes on a key relationship for the capitalist accumulation”, Economica, v.3, n.1, p.5-33, jun., 2001.

Pavani, C. "O capital de risco no Brasil - Conceito, evolução e perspectivas", Rio de Janeiro, e-papers, 2003. 
Peirone, D. "Knowledge and venture funding: complementarities and financial contracts", Industrial and Corporate Change, 16(5), p.851-873, 2007.

Rechtman, M.; Brito, B. BRICS and private equity, Rio de Janeiro: FINEP, 2005.

Rodrik, D. "Falsa promessa da liberalização financeira", Valor Econômico, 12/1/2007.

Rosenberg, N. "Why do firms do basic research (with their own money)?", Research Policy, v.19, p.165-174, 1990.

Schumpeter, J.A. A teoria do desenvolvimento econômico, São Paulo: Abril Cultural, 1982.

Studart, R. "Financial repression and economic development: towards a post-keynesian alternative", Review of Political Economy, 5(3), p.277-298, 1993.

Zysman, J. Governments, markets, and growth: financial systems and the politics of industrial growth, Oxford: Martin Robertson, 1983.

. "Financial systems and technological innovation", paper presented at the Conference on Innovation Diffusion, Veneza, 17-21 mar., 1986.

\section{Sítios eletrônicos indicados}

$<w w w . b n d e s . g o v \cdot b r>$

$<w w w . c v m . g o v \cdot b r>$

$<w w w$.finep.gov.br>

$<$ www.mct.gov.br>

ENDEREÇO PARA CORRESPONDENCIA:

Luiz Martins de Melo - luizmelo@fujb.ufrj.br; luizmelo@ie.ufrj.br Avenida Pasteur, 250, Urca

Instituto de Economia - IE-UFRJ

22290-240 - Rio de Janeiro (RJ)

Tel: (21) 2543-5816 